\title{
Is boredom an animal welfare concern?
}

\author{
Article \\ Published Version
}

Open Access

Meagher, R. (2018) Is boredom an animal welfare concern? Animal Welfare, 28 (1). pp. 21-32. ISSN 0962-7286 doi: https://doi.org/10.7120/09627286.28.1.021 Available at https://centaur.reading.ac.uk/78887/

It is advisable to refer to the publisher's version if you intend to cite from the work. See Guidance on citing.

To link to this article DOI: http://dx.doi.org/10.7120/09627286.28.1.021

Publisher: UFAW

All outputs in CentAUR are protected by Intellectual Property Rights law, including copyright law. Copyright and IPR is retained by the creators or other copyright holders. Terms and conditions for use of this material are defined in the End User Agreement.

\section{www.reading.ac.uk/centaur}

\section{CentAUR}

Central Archive at the University of Reading

Reading's research outputs online 


\title{
Is boredom an animal welfare concern?
}

\begin{abstract}
RK Meagher
School of Agriculture, Policy \& Development, University of Reading, Whiteknights, PO Box 237, Reading RG6 6AR, UK; email: rkmeagher@gmail.com

Abstract

Boredom, while often casually attributed to non-human animals by both laypeople and scientists, has received little empirical study in this context. It is sometimes dismissed by others as anthropomorphic or a trivial concern in comparison to other welfare problems faced in captivity. Recent work on human boredom, however, has led to evidence that, far from being trivial, it can have serious consequences in the form of risky behaviour and reduced physical as well as mental health, and potentially contributes to social problems. Research on mink, supported by older literature on farm and laboratory animals, suggests that monotonous, stimulus-poor environments can induce an increased motivation for diverse stimuli, consistent with the experience of boredom. This experience is likely to be aversive and may lead to problems such as depression-like states or self-injurious behaviour if not addressed. Boredom should therefore be treated as an important welfare concern. Research is needed to find practical ways of identifying this state and to determine how widespread it is across species and which animals are most at risk. Possible ways of alleviating or avoiding this problem include offering animals in our care $a$ choice in the level of stimulation they experience and opportunities to experience appropriate cognitive challenge.
\end{abstract}

Keywords: animal welfare, boredom, emotional states, exploratory behaviour, individual differences, sensation-seeking

\section{Introduction}

Boredom is... the shriek of unused capacities.

Saul Bellow, The Adventures of Augie March (1949)

Many members of the general public do not hesitate to attribute emotional states, such as boredom, to their pets and, perhaps less ubiquitously, to other animals they encounter, such as those in zoos and aquaria. Scientists, too, have referred to boredom as a welfare concern in captive animals for decades (eg Wood-Gush \& Beilharz 1983). However, other scientists believe that such statements are anthropomorphic (eg Anderson 2004; Harfeld 2013), and indeed there has been little systematic research on the topic of boredom in non-humans to justify using the term. This leaves us with a few major questions. First, can animals really experience boredom? If so, which ones do? Finally, how much does it matter?

The topic of whether non-human animals (hereafter simply called 'animals') subjectively experience any affective states in the same way as humans do is complex and has been covered elsewhere (eg Mendl \& Paul 2004). The general consensus, supported by behavioural, physiological and neurobiological evidence as well as evolutionary arguments, is that other animals are capable of experiencing emotions (Low et al 2012). While animals may not have analogues of every human emotional state, if they can experience states such as fear and frustration, there seems little reason to dismiss the possibility they might also exhibit boredom-like states.

In this paper, I will briefly review our understanding of boredom and its symptoms based on humans, and how this has been applied to animals. This includes a discussion of the ongoing challenges with assessing boredom in this context. I will then outline why boredom is important to animal welfare, and finally suggest some possible approaches to addressing the problem.

\section{What is boredom and how is it detected?}

\section{The concept and its assessment in humans}

Boredom, as traditionally defined based on human experience, is essentially a negative affective state caused by a lack of desired stimulation or behavioural opportunities. It can be divided into that which is extrinsically caused by such situations and that which stems from intrinsic causes, such as attentional difficulties, that can make it difficult to engage in meaningful activity (Eastwood et al 2012); the latter is what the French would call ennui. Boredom bears some similarity to, but can be distinguished from, frustration (Mikulas \& Vodanovich 1993; van Tilburg \& Igou 2017). It is consistently self-reported by most people in situations where behavioural opportunities are constrained and little variation in stimulation is available, in either the long or short term (see, eg Berlyne 1960). Extremely 'boring' situations, such as 
sensory deprivation seem to lower the threshold for stimuli to elicit interest; for example, people under these conditions would ask for stimuli they would otherwise find dull, such as recorded stock market reports (Bexton 1953). However, the likelihood of a given situation or level of monotony resulting in boredom differs between and within individuals (eg Drory 1982; Mercer-Lynn et al 2014).

As with other emotions, the subjective experience of boredom is likely accompanied by cognitive, behavioural and physiological changes (see Mendl et al 2010). It is associated with a perception of time passing slowly, sometimes used in self-report measures as a proxy for boredom itself. Behaviourally, symptoms range from lethargy to restlessness, both within and between individuals, and physiologically, both increases and decreases in arousal levels relative to people not experiencing boredom are sometimes reported (for reviews, see Russell 1983; Eastwood et al 2012). Changes in arousal may vary depending on whether the situation is seen as avoidable (inducing agitation and high arousal: Mercer-Lynn et al 2014), or whether boredom is induced by low levels of stimulation versus monotonous but intense stimulation (Berlyne 1960). There seems to have been little direct comparison of the different situations that can result in boredom to elucidate these relationships. In general, though, bored people seem to experience periods of dullness or drowsiness interrupted by periods of irritability or attempting to attain stimulation (Berlyne 1960; Burn 2017), with the lethargy perhaps increasing over time (Inglis 1983). Helplessness and/or apathy is hypothesised to develop if no satisfying stimulation is found (Wemelsfelder 2005).

It is thus unclear from the literature whether any specific symptoms beyond the aversive feeling and perception of the situation as deficient in novel or variable stimulation are definitional requirements of boredom. Some frameworks focus on the role of meaning (Eastwood et al 2012), going back to Viktor Frankl's theory (1985; originally published in 1946) that people's affective response to a situation depends on the meaning or purpose they find in it. Relatively monotonous tasks or situations can be welltolerated if people perceive a purpose in them (eg astronauts on long-duration space missions: Britt et al 2017; similar arguments could be made for parents caring for newborns or scientists choosing to conduct repetitive tests and observations), and self-reported 'purpose in life' has been shown to negatively correlate with tendency to experience boredom (Weinstein et al 1995; Melton \& Schulenberg 2007).

Some authors have suggested that boredom should be divided into subtypes that would explain the contradictory results regarding arousal levels. For example, Malkovsky and colleagues (2012) describe two types of boredom-prone individuals: an 'agitated' type, wherein people who typically exhibit high arousal and attention deficits or hyperactivity are highly susceptible to the extrinsically caused form of boredom described above, and an 'apathetic' type, wherein people with lower arousal may be more prone to boredom from intrinsic causes. Fahlman et al (2013), by contrast, proposed a scale for measuring state (as opposed to trait) boredom that considers arousal changes in either direction (high and low arousal) in combination with the cognitive features of the state (labelled disengagement, inattention and time perception). The authors argue that since either high or low arousal could be indicative of boredom even within individuals, as the literature described above suggests, both should be considered.

Regardless of how it is defined, boredom is now perceived, at least in the Western world, as a very common human experience, inspiring a plethora of books and popular press articles in recent years. Evidence supports this belief, although some aspects of susceptibility to boredom are culturally variable (Sundberg et al 1991; Gaygisiz 2010; Ng et al 2015). Some have argued that it was not experienced by all humans but rather is a strictly modern phenomenon, arising after the Industrial Revolution when people began to have more time unfilled by tasks necessary to keep themselves and their families alive (Toohey 2011). Similarly, boredom has been suggested to be increasing in prevalence over time as technological advances increase the amount of novel stimulation available such that novelty becomes routine, and focusing on meaningful stimulation becomes more difficult (eg Aho 2007). The word 'boredom' did not even exist in English until the 18th century (Burn 2017; Oxford English Dictionary 2017). Nonetheless, the philosopher Seneca's description of life feeling sickeningly monotonous (1917; p 181) written in the first century suggests that something like this state did exist in the ancient world (typically described by the Latin word taedia [tedium], although Seneca instead termed it 'nausea': Toohey 2011).

One might question whether we should expect other species to experience an emotion that may not even be universal among humans. However, captive animals often face a situation equivalent to that of modern humans: when most basic physical needs are being met by their human caretakers and little time needs to or even can be spent in acquiring food or searching for mates, they are left with more 'unfilled' time (with no urgent motivation to perform any specific behaviour) than their species likely encountered throughout most of their evolutionary history. Because of this lack of evolutionary preparation and therefore adaptive mechanisms to respond to the absence of immediate biological needs, McFarland (1989) hypothesised that animals would likely find this state, which he called 'limbo', aversive (see, also, Webster 2005 for agreement and a discussion of how this might be manifest).

\section{What evidence do we have of boredom in animals?}

With colleagues, I set out to define boredom operationally in such a way that we could investigate the possibility of its existence in non-human animals. The contradictory behavioural signs and arousal changes in humans make such investigation challenging; human studies of boredom typically rely on self-report as the principal measure. Nevertheless, the central component of boredom is a lack of stimulation at the level or degree of variability preferred. Therefore, evidence of motivation for general stimulation should be a consistent symptom of this state. We focused on this key symptom, defining boredom as "a negative [emotional] state induced by barren conditions that causes 
an increased, generalised interest in diverse stimuli" (Meagher et al 2017). Other ethologists have proposed similar definitions (Kirkden 2000), although following the human models above, some have suggested that demonstrating sub-optimal (or declining) arousal as the physiological component of the emotion is also essential (Burn 2017). These definitions and the associated empirical work have focused on the extrinsically caused form of boredom, since this allows for experimental manipulation and validation of whether the situation is aversive.

Based on our definition, we assessed interest in diverse stimuli in American mink (Neovison vison) (Meagher \& Mason 2012; Meagher et al 2017). The use of multiple types of stimulus was important for establishing that the mink were motivated for change generally, rather than the stimulus allowing them to fulfil a specific frustrated motivation (Mason \& Burn 2018). Stimuli ranged from those predicted a priori to be aversive to mink, such as cues from natural predators or puffs of air, to those predicted to be rewarding, such as prey cues or a moving object to chase; some novel stimuli with no obvious biological relevance were judged to be neutral. Our indicators of 'interest' were time oriented to, time in contact with, and latency to contact the stimuli. Mink housed in then-standard, non-enriched farm cages (simple rectangular cages furnished only with a nest-box) were expected to show more of these indicators of interest than those housed in large, structurally complex cages with new manipulable items added periodically; these cages had been shown to improve welfare and mink would work to gain access to them (Dallaire et al 2012). The findings accorded with this prediction, with the housing effects on boredom-like responses most consistently found using the time oriented to and in contact with stimuli rather than latencies to contact.

Older work typically investigated only one stimulus at a time but provided similar evidence that animals in restricted captive environments are motivated for stimulation. For example, rhesus macaques (Macaca mulatta) will perform operant behaviour for visual stimulation (Butler 1953) and rats (Rattus norvegicus), for simple changes in light intensity (reviewed by Berlyne 1960). Several species seem to seek out stimulation, in ways ranging from increased exploratory behaviour (eg pigs [Sus scrofa]: Stolba \& Wood-Gush 1980; Bracke \& Spoolder 2008; calves: Mackay \& Wood-Gush 1980; female rats: Zimbardo \& Montgomery 1957) to changes in diet (increased voluntary salt intake in horses [Equus caballus]: Porvaldsdóttir 2014).

In summary, the evidence suggests that many farm and laboratory animals will work to obtain stimulation, and this may suggest that they experience an aversive, boredom-like state when exposed to monotonous or stimulus-poor environments. If this is the case, boredom is likely to be an animal welfare problem.

\section{What still needs to be done?}

More systematic work looking at responses to a range of stimuli is still needed to test how widespread this state is across species when housed in monotonous conditions.
Ideally, this research will incorporate additional welfare indicators, to see whether the motivation as assessed by these arrays of tests is truly associated with poor welfare on an individual level, and to assess convergent validity of other putative boredom indicators. Burn (2017) reviews the array of potential indicators that could be used to study not only the motivation for novel stimuli or conversely, the aversion to monotonous, stimulus-poor environments (eg preference and cognitive bias tests and sensation-seeking behaviour), but also other likely signs of boredom. This includes indicators for changes in arousal; disrupted sleep; and slowed perception of time to reflect the feeling of time 'dragging' reported by bored humans, measured through means such as interval timing paradigms or earlier onset of anticipatory behaviour (Burn 2017).

Several challenges must be confronted in this research. To employ the technique of assessing responses to diverse stimuli, there is a need to identify stimuli that are aversive, neutral or rewarding for the species in question, which has proven challenging (Meagher et al 2017). Ideal measures of boredom might also include physiological components to better capture the multi-dimensional nature of the state (cf Fahlman et al 2013), as suggested above. Based on the symptoms described in humans, we might typically expect bored animals to show low or declining average levels of arousal (evident in, eg decreasing beta waves and increasing alpha waves in EEG: Burn 2017). This pattern may nonetheless vary with situation (stimulus deprivation or monotony; see, The concept and its assessment in humans). For animals, then, the declining pattern is most likely to occur in barren cages on farms or in homes, and less likely in environments where there are high levels of disturbance yet limited behavioural opportunities (eg some shelters). The other challenge with arousal measures is choosing timelines over which to conduct the work to test these hypotheses. For effects of long-term housing, this may be difficult given the expectation that declines will not be smooth and constant, and the possibility that arousal that has already reached a stable low level might in fact better characterise resulting apathy. Finally, the proposed behavioural indicators of the state are not specific to boredom: both disrupted sleep and abnormal behaviour, for example, can have many causes (as acknowledged by Burn 2017). Perhaps for this reason, the locomotor stereotypies studied in the mink were not reliably linked to boredom-like states (Meagher et al 2017). One of Burn's suggested solutions is to attribute abnormal repetitive behaviours to boredom after ruling out other suspected causes, and indeed, we do need to ensure that any single symptom, such as abnormal behaviour or a response to a particular type of stimulus cannot be explained by a specific frustrated motivation rather than a general motivation for stimulation before ascribing it to boredom. However, identifying and ruling out each possible motivation may be difficult and timeconsuming, and so there is some danger 'boredom' will continue to be used as a sort of 'catch-all' explanation for unexplained undesirable behaviours (as for, eg by laypeople discussing crib-biting in horses: Litva et al 2010), rather 
than to refer to a clearly defined and measurable state. It is thus important that further research is done to identify patterns of indicators that can be combined to help to distinguish boredom from other negative states, and to better understand its causes across species.

Beyond these theoretical difficulties, various challenges certainly also remain for implementing measurements of boredom as a component of practical welfare assessments. Intensive testing of responses to an array of stimuli is obviously difficult under time and other practical constraints. Measuring slowed time perception, as suggested by Burn (2017), while of great fundamental interest, is similarly time-consuming and currently requires an intensive period of training the animals. Many measures of arousal, such as EEG recordings, are also impractical for applied settings. While our mink research suggests that some spontaneous behaviour, such as alert inactivity, could reflect boredom, this relationship has thus far puzzlingly been present only under enriched housing conditions and not those in which boredom would be expected to be a larger problem (Meagher et al 2017). Ideally, easily observable spontaneous behaviours can be identified; this might include behaviour such as yawning (Burn 2017) or even facial expressions. Qualitative behaviour analysis is one suggested method of practical assessment but has not yet been validated (Meagher et al 2017).

\section{Is boredom a 'lesser evil'?}

Apathy is the condition of not caring. Boredom... boredom

is just a slumber one can be roused from

Jacob Tierney, The Trotsky (2010)

Given the evidence that many captive animals experience fear, pain, and perhaps depression-like states, which are widely accepted as serious welfare problems, boredom might be considered a lesser of many evils. In humans, too, boredom has received less scientific attention than other common negative states have (see, eg, Eastwood et al 2012). This is perhaps unsurprising, since it is not in itself a disorder, as depression and clinical anxiety are. It has been judged as comparatively less intense in theoretical frameworks of emotions (Plutchik 2001), and to have a weaker negative valence than other common negative emotional states, such as depression or anger (as rated by laypeople in the United States: von Tilburg \& Igou 2017) Boredom should also be easily reversible, as the above quote implies, whereas states like depression are much harder to treat. On the other hand, unalleviated boredom in humans can have serious sequelae, as outlined below, which have led Eastwood and colleagues (2012) to argue that boredom should no longer be dismissed as 'trivial'; a similar case has been made for animals (Wemelsfelder 2005).

\section{Associated emotional and physical health problems in humans}

People who are prone to boredom exhibit higher rates of depression and anxiety, as well as physical health problems that can be attributed to somatisation, such as headaches (Sommers \& Vodanovich 2000). Boredom has also been linked to loneliness (for a review, see Bloomfield \& Kennedy 2006), although the direction of causality has not been established. Furthermore, boredom can complicate other health problems, as reviewed by Eastwood and colleagues (2012): it impedes treatment of psychiatric disorders and brain injury (eg Todman 2003; Frasca et al 2013 report a similar effect from lack of environmental enrichment, which may induce boredom).

\section{Potentially harmful behavioural consequences in humans}

Boredom may cause harm both directly and indirectly through its behavioural effects. It has been linked to lower physical activity (Britton \& Shipley 2010). It can impair concentration in dangerous situations (eg truck drivers: Drory 1982), and is reported to motivate intentional risky or self-harming behaviour, from bungee jumping (Michel et al 1997) to drug abuse (eg Samuels \& Samuels 1974; Abiona et al 2015) or risky sexual behaviour (eg German \& Latkin 2012; Abiona et al 2015) — part of a phenomenon known as sensation-seeking. Even temporary boredom resulting from monotonous tasks induces some people to self-administer mild electric shocks (Wilson et al 2014; Havermans et al 2015; Nederkoorn et al 2016). More long-term boredom (Chapman et al 2006) or conditions that may induce it (solitary confinement, which involves lack of stimulation plus social deprivation: Kaba et al 2014) has been linked to increased risk of more serious self-harm, and to suicide risk (Maltsberger 2000). On a societal level, boredom is believed to contribute to problems such as violence (eg in prison populations: HM Chief Inspector of Prisons 2015; between nursing home residents: Snellgrove et al 2013; even suggested as a cause of glorifying war: Kustermans \& Ringmar 2011). Ultimately, perhaps through some combination of the emotional, physical and behavioural effects, boredom may even reduce lifespan (Bloomfield \& Kennedy 2006; Britton \& Shipley 2010).

\section{What consequences can be expected in animals?}

The mechanisms by which boredom endangers mental and physical health in humans are not fully understood. It is possible that some of the more serious consequences, such as depression and severe self-harm, are mediated by the perceived lack of meaning in people's lives (Maltsberger 2000; Bloomfield \& Kennedy 2006), potentially making it less likely that similar patterns would be very widespread across species. Although it has not been directly studied, however, we do have some reason to believe that boredom could have detrimental effects on animals.

Similar changes in behaviour to those that cause indirect harms in humans might be seen. While risk-taking per se and its negative consequences have not been directly demonstrated as a consequence of stimulus-poor housing or monotony in animals, increased novelty-seeking or exploration like that described above in such housing conditions is typically considered risky under natural conditions (eg Reader 2015) or is accompanied by reduced risk avoidance (for example, see Toledo-Rodriguez \& Sandi 2011 but cf van 
der Staay et al 2017). While captive animals typically face few life-threatening risks, this behaviour could still pose some danger. Similarly, at both the group and individual levels, there is some evidence consistent with the idea that bored animals, like bored humans, might make choices that would ultimately be bad for their health, such as abusing drugs, if given the chance. Animals housed in barren environments are more likely to consume and prefer ethanol (eg de Carvalho et al 2010) and have a higher preference for and response to cocaine (Zakharova et al 2009; Nader et al 2012). Some rats in individual housing will self-administer corticosterone, suggesting they are seeking higher arousal, even activation of systems typically associated with stress (Piazza et al 1993). Bored animals, like people, might even also eat unhealthy diets given the choice: lack of enrichment has been linked to increased salt intake, as stated above, and to sucrose-seeking behaviour (van der Harst et al 2003; Grimm et al 2008; de Carvalho et al 2010). The mink in nonenriched conditions that induced signs of boredom also ate more treats (Meagher \& Mason 2012).

A greater concern in most captive environments is that boredom has been hypothesised to cause direct self-harm (eg primates: Honess \& Marin 2006; turtles: Burghardt 2013). Consistent with this hypothesis, the most exploratory farmed mink in one study were also the most likely to perform abnormal self-directed tail-biting behaviour, which can cause injury (Svendsen et al 2013); this could be explained by individuals which are the most motivated to explore suffering more from boredom in standard farm cages (see Mettke-Hoffmann 2000, for a similar relationship between exploration and featherplucking in parrots). Environmental enrichment for primates can reduce social aggression and self-harm (for a review, see Honess \& Marin 2006). Boredom could even be one factor contributing to the finding that barrenhoused mice (Mus musculus) and isolation-housed rats have shorter lifespans (Menich \& Baron 1984; Arranz et al 2010), although it is unlikely to be the sole cause.

Aside from any potential damage to health and longevity, boredom per se is a concern given the growing recognition that good welfare is not merely the absence of negative states, but also the presence of positive ones (eg Mench 1998). While boredom is in itself a negative state, it also reflects a perceived monotony, which implies that there are no pleasant interruptions to the routine. If captive animals are kept in ways that do not offer positive breaks from monotony, and experience a perceptual slowing of time like that described in bored humans above, they might experience life as very long, as well as of very poor quality. The evidence above of their motivation for even very basic forms of variety indicates that they do find such situations aversive. Altogether, the evidence and our theoretical understanding suggest that while very short-term state boredom may be a lesser concern than some of the better-studied welfare problems experienced by captive animals, if allowed to persist, it could have a serious impact on lifetime welfare. The state and its possible correlates need to be better understood in order to more effectively judge its relative impor- tance in overall welfare (see Fraser 1995; Webster 2005, for discussion of how such judgements are made).

\section{Are some animals more likely to experience boredom than others?}

What evidence we have of boredom-like symptoms in captive animals comes largely from a small number of mammalian species, and more systematic testing is needed to determine how widespread a problem this is at both the species and individual level. There are, however, evolutionary and ecological hypotheses that predict which animals might be most at risk, and when. These can be divided into hypotheses regarding innate or permanent differences between species and individuals, and those on changes within the lifetime of the animal.

\section{Innate boredom susceptibility}

Two hypotheses regarding innate risk of boredom have been outlined previously (Meagher \& Mason 2012; Burn 2017). First, given that boredom is hypothesised to motivate exploration of new environments and resources (see Burn 2017), one might predict that generalist, opportunistic species, which are adapted to make use of a wide range of habitats and foods (see Mettke-Hofmann 2014), might be more susceptible. Second, another hypothesised function of boredom is to motivate innovation (Lilley et al 2017), which suggests that particularly intelligent and innovative animals might suffer most when not given opportunities to exercise these abilities (Mason et al 2013; Burn 2017).

Characteristics, such as intelligence, may predict boredom susceptibility at the individual level, as well. Individual humans certainly differ in how easily they get bored, known as 'boredom proneness', a trait which correlates positively with other well-established personality traits including extraversion and impulsivity (see Zuckerman 1971). The idea that it may be linked to intelligence has attracted considerable interest, although relationships in both directions have been predicted. Intelligent people might desire more stimulation to occupy their minds, as suggested above for animals, but also be better able to entertain themselves, whether by thinking through problems or coming up with innovative ways to provide their own stimulation (see Leong \& Schneller 1993; Harris 2000). Evidence in either direction is somewhat limited, although some early studies suggested intelligence was a risk factor for boredom in workers (see Drory 1982). Intelligence is, in some cases, positively correlated with sensation-seeking (eg Ripa et al 2001), and relatedly, with use of stimulant drugs (Carrol \& Zuckerman 1977), consistent with a higher motivation for stimulation. The causal relationship could go both ways: sensationseeking early in life has been found to predict later IQ, which was suggested to be due to sensation-seeking resulting in 'enrichment' and therefore enhanced cognitive development (Raine et al 2002). On the other hand, Cladellas et al (2017) report a negative relationship between sensation-seeking and academic performance when measured at the same time. This might be taken as support for the hypothesis that more intelligent people get bored less, and therefore seek external stimulation less, but intelligence is not necessarily reflected in academic performance. 
Comparative evidence across species is currently too limited to draw firm conclusions on intelligence and species ecology as risk factors. Burn (2017) discusses ways in which these hypotheses could be tested, which could strengthen the predictions. The limited evidence we have does suggest that perhaps generalist species are particularly likely to seek stimulation in captivity (Kirkden 2000; Mason et al 2013). Less is known about relationships between exploratory behaviour or sensation-seeking and intelligence in animals. This is due, in part, to the struggle to agree on a definition of intelligence and way to measure it as a unitary concept rather than relying on similarity to human abilities (see, for example, van Horik \& Emery 2011) — a challenge which is likewise faced to some degree in human research (see, for example, Sternberg 2000). Nonetheless, if these hypotheses regarding species' differences are correct, there are important implications. Some of the species that would be predicted to be at high risk might pose quite a challenge for alleviating boredom. Octopus (Octopus dofleini), for example, are widely recognised to be intelligent, are typically generalists (Mather et al 2012) and neophilic (Mather \& Anderson 1999), but are so removed from humans that it may prove difficult to identify their needs.

\section{Changes in boredom susceptibility within the lifetime}

In addition to such innate differences, age and experience might play a role in determining animals' preferred levels of stimulation. Susceptibility to boredom might therefore be expected to vary with age or developmental stage. In humans, teenagers notoriously often complain of boredom (see, for example, Shaw et al 1996). Sensation-seeking typically peaks during adolescence, with trajectories differing by sex in ways that mirror other aspects of maturation (Shulman et al 2015). Evidence suggests that this may have more to do with situational factors than physiological development (Romer 2010); one such factor might be that this is an age when they are first being exposed to much of the adult world and have not learned to control impulsive responses to it. A similar pattern could be predicted in animals, since the juvenile period is similarly a time of exposure to new environments and using this period for exploration and information-gathering before needing to survive on their own is likely to be adaptive (see, for example, Miller et al 2015). Juveniles of some species do exhibit more curiosity than mature animals do (for a review, see Hall et al 2018). A higher exploratory motivation, as suggested above, is expected to make animals more prone to boredom when information-gathering is not possible.

Prior experience is also known to influence exploratory tendencies (for a review, see Reader 2015), and may generally influence the preferred level of stimulation or arousal (eg Lockard \& Haerer 1968; Wemelsfelder \& Birke 1997). Early experience can affect traits related to boredomproneness, such as response to novelty, impulsivity and risk-taking in rodents, but evidence for the direction of these effects is somewhat mixed (eg Berardo et al 2016; Garcia et al 2017 report a relevant trait was increased in stressed or barren-housed males but Ferland et al 2014 found it decreased). The early environment also affects cognitive traits, such as innovation or problem-solving ability, suggested above to be relevant to boredom (eg Quinn et al 2016). All of this suggests that previously experienced environments are likely to play a role in determining whether an animal will experience boredom in its current environment. This poses a potential problem because we generally advocate providing stimulating environments for young animals to aid in development and improve adult welfare (eg Schrijver et al 2002; Meagher et al 2015), but these animals might then develop intelligence and skills for which they will have no use - the 'unused capacities' of which Bellow (1949) spoke. If higher levels of intelligence are indeed linked to increased susceptibility to boredom, or if a complex early environment simply sets a preference for a higher typical level of stimulation, this creates an ethical quandary unless we can continue to offer adequate stimulation throughout the animal's lifetime.

\section{Working towards solutions}

Where we find evidence that captive animals are experiencing boredom-like states, the obvious next step is to find ways of alleviating it or preventing it for future animals in the same setting. To begin with alleviation, the most obvious means by which this could be accomplished is environmental enrichment, which can increase overall stimulation or behavioural opportunities. Although this is already commonly recognised, the approach to enrichment might be tailored differently for reducing boredom than it is for addressing other welfare problems such as specific frustrations. When there is a specific behavioural need to target, typically this would suggest one or a few possible substrates to offer, which is not the case with boredom. Instead, a guiding principle might be to consider what capacities the species has in the wild and which ones are not being developed or put to use in the captive environment. Such capacities might include specific skills reflected in the obvious, species-specific, and relatively stereotyped specific behaviour patterns which animals are likely intrinsically motivated to perform (and whose prevention is thus more likely to lead to specific frustration: Mason \& Burn 2018), but also more general, flexible capacities including mental abilities. Disuse of the latter might be more likely to lead to boredom, although this hypothesis still needs testing. Fraser (1999) suggested that such an approach to improving animal management would be an appropriate way of applying the concept of telos (the essential nature of the animal) raised in ethical discussions regarding animals in animal welfare science. Considering boredom reduction from this perspective might influence both the type of enrichment offered, and the way in which it is presented.

With regard to how to present enrichments, predictability is one aspect that must be considered. If boredom is brought about by a lack of novel or 'surprising' stimulation, as found in monotonous environments (Berlyne 1960), then providing variable, less predictable stimulation would clearly address this. However, this strategy needs to be employed carefully; it is well established that unpredictability can cause stress, as in the case of unpredictable aversive events, or frustration, which is often seen when formerly predictable appetitive stimuli are not presented 
when expected (for a review, see Bassett \& BuchananSmith 2007). Beneficial unpredictability has been studied less, but Bassett and Buchanan-Smith (2007) do conclude that using unpredictable schedules for appetitive stimuli such as food might improve welfare. The optimal level of predictability seems likely to vary not only with the type of stimulus involved but also between species and individuals (Morgan \& Tromborg 2007), including their past experience with predictability (Bassett \& Buchanan-Smith 2007). The question, then, is how can we reduce the risk of boredom for animals in our care without causing undue stress to those that are less boredom-prone and more fearful?

Offering choice or control over the experience of enrichment could resolve this problem. Not only does it reduce the risk of inducing stress in animals whose preferred levels of stimulation are lower, because they are not forced to interact with the stimuli, but the choice itself may improve welfare (see Franks \& Higgins 2012) and could therefore be considered a form of enrichment. Giving animals such control is one means of allowing them agency, which has been defined as "inner-motivated... engagement with the environment" (Špinka 2019; this issue). Such agency has been suggested to be a key element of animal welfare (Špinka \& Wemelsfelder 2011). Although this argument regarding animals has not referred to boredom specifically, there is a growing perception that such engagement is key to avoiding boredom in humans (Eastwood et al 2012; Falman et al 2013). It has been suggested that the high incidence of boredom in adolescent humans is not just due to exposure to novelty and elevated motivation to explore but the fact that these coincide with the adolescents having limited autonomy or control over how they spend their time (Eastwood et al 2012). In a comparison between countries, too, more 'hierarchical' cultures in which individuals may perhaps feel less autonomous have been linked to higher prevalence of boredom (Gaygisiz 2010), and sensationseeking has been linked individually to need for autonomy (Zuckerman \& Link 1968). Boredom, then, could be hypothesised to be one negative consequence of loss of agency in animals as well, such that offering enrichments in ways that afford animals choice would not only resolve the problem of within-group differences in abilities or preferred stimulation levels but also potentially address a deeper underlying cause of boredom.

In terms of what type of stimuli to offer to best promote longterm engagement, cognitive enrichment might be ideal. Cognitive challenge, at a level appropriate to the abilities of the animals, has been suggested as important to long-term welfare because it allows animals to exercise mental capacities that are otherwise little used in typical captive environments and to express control over their environments (Meehan \& Mench 2007; Clark 2013) — both factors suggested here to be important for boredom specifically. Meehan and Mench (2007) invoked the old concept of 'eustress' (ie stress that is somehow good for the animal), suggesting the temporary frustration or anxiety that might be induced by challenge would ultimately be beneficial if the animal is able to meet the challenge. A total lack of such stress could be considered a component of 'boring' situations, explaining why boredom can induce seeking of even typically aversive stimuli, as described above. Cognitive challenge is a way of providing mild, short-term 'stress' or increased arousal that is less likely to be harmful to the animal than some sensation-seeking behaviours are. Csikszentmihalyi (1975) proposed that, for humans, working on a task that is well-matched to one's abilities such that it is very challenging but achievable leads to an enjoyable state of complete engagement that he termed 'flow'. Cognitive enrichment that is successfully matched to the animals' abilities might similarly promote the type of engagement that prevents boredom. Cognitive enrichment also has the added benefit that it does not need to involve intense stimuli that would affect other individuals within the enclosure.

Finally, we can consider whether we can help to prevent boredom by rearing animals in ways that would make them less susceptible. One consideration is the hypothesised role of attentional deficits in intrinsically caused boredom in humans. Both Attention Deficit/Hyperactivity Disorder and damage to parts of the brain involved in selective attention are associated with high boredom proneness in humans; this link is believed to be due to difficulties in engaging with stimuli resulting from these conditions (Eastwood et al 2012; Burn 2017). Raising animals that are likely to express such deficits in attention regulation should therefore be avoided, because if the same relationship exists in nonhumans, they might be prone to boredom that is not affected by enrichment. Impulsivity, which is related to attention regulation disorders, can be induced by early life adversity in both humans (Lovallo 2013) and rats (Wood et al 2006; Toledo-Rodriguez \& Sandi 2011) and selected for genetically in animals (eg dog breed differences: Fadel et al 2016; ADHD rodent models: Hayward et al 2016), indicating that it is possible to use both breeding and early life management to reduce these problems.

\section{Animal welfare implications}

The limited evidence we have, together with evolutionary theory and the similarity between situations faced by many captive animals and those that induce boredom in humans, suggest that these animals may experience boredom-like states. This pervasive human experience, while sometimes mild and likely functional, spurring exploration and learning, can have severe and even lifethreatening consequences when people are unable to exert control to change the situation that rouses it. It is worth investigating the extent to which a similar phenomenon is expressed in animals; given the conditions in which they are frequently kept, it might well be one of the most common problems affecting the health and welfare of zoo, laboratory, farm and companion animals worldwide. Using indicators such as hyperresponsiveness to stimuli and changes in time perception and applying them to a wide range of species could allow us to better understand a potential root cause of various behavioural problems in captive animals, and therefore to develop more effective solutions, addressing the issue 
before these 'downstream' effects develop. Ultimately, this should help us in working towards providing captive animals with "a life worth living" (FAWC 2009).

\section{Acknowledgements}

Many thanks to Georgia Mason and Charlotte Burn for interesting discussions on this subject, to the editors of this special issue for inviting me to contribute, and to the participants in the Animal Welfare Reconsidered workshop for their feedback. Thanks also to the Wissenschaftskolleg zu Berlin (WIKO) for supporting and facilitating the workshop.

\section{References}

Abiona T, Balogun J, Adefuye A and Anguh I 2015 Understanding HIV risk behaviors in prison: a qualitative study among recently released inmates. International Journal of Prisoner Health I I: 196-208. https://doi.org/ I0.1 I08/IJPH-I I-20|4-0043

Aho K 2007 Simmel on acceleration, boredom, and extreme aesthesia. Journal for the Theory of Social Behaviour 37: 447-462. https://doi.org/I0.1 I I I/j.1468-59|4.2007.00345.x

Anderson B 2004 Time-stilled space-slowed: how boredom matters. Geoforum 35: 739-754. https://doi.org/10.1016/j.geoforum.2004.02.005

Arranz L, De Castro NM, Baeza I, Maté I, Viveros MP and De la Fuente M 2010 Environmental enrichment improves agerelated immune system impairment: long-term exposure since adulthood increases life span in mice. Rejuvenation Research 13: 4| 5-428. https://doi.org// 0.1089/rej.2009.0989

Bassett L and Buchanan-Smith HM 2007 Effects of predictability on the welfare of captive animals. Applied Animal Behaviour Science 102: 223-245. https://doi.org/I0.1016/j.applanim.2006.05.029

Bellow S 1949 The Adventures of Augie March. The Alison Press: London, UK

Berardo LR, Fabio MC and Pautassi RM 2016 Post-weaning environmental enrichment, but not chronic maternal isolation, enhanced ethanol intake during periadolescence and early adulthood. Frontiers in Behavioral Neuroscience 10: 195. https://doi.org/ 10.3389/fnbeh.2016.00195

Berlyne DE 1960 Conflict, Arousal, and Curiosity. McGraw-Hill: New York, NY, USA. https://doi.org/I0.1037/I I I64-000

Bexton WH 1953 Some effects of perceptual limitation in human subjects. McGill University: Montreal, Canada

Bloomfield LJ and Kennedy G 2006 Killing time: Excess free time and men's mortality risk. Proceedings from the Time Use and Gender Seminar Pp I-26. Sydney, Australia. Social Policy Research Centre: University of South Wales, Australia

Bracke MBM and Spoolder HAM 2008 Novel object test can detect marginal differences in environmental enrichment in pigs. Applied Animal Behaviour Science 109: 39-48. https://doi.org/ 10.1016/j.applanim.2007.01.014

Britt TW, Sytine A, Brady A, Wilkes R, Pittman R, Jennings $\mathbf{K}$ and Goguen K 2017 Enhancing the meaningfulness of work for astronauts on long duration space exploration missions. Aerospace Medicine and Human Performance 88: 779-783. https://doi.org//0.3357/AMHP.4875.2017
Britton A and Shipley MJ 2010 Bored to death? International Journal of Epidemiology 39: 370-37I. https://doi.org /10.1093/ije/dyp404

Burghardt GM 2013 Environmental enrichment and cognitive complexity in reptiles and amphibians: Concepts, review, and implications for captive populations. Applied Animal Behaviour Science 147: 286-298. https://doi.org//0.1016/j.applanim.2013.04.013

Burn CC 2017 Bestial boredom: a biological perspective on animal boredom and suggestions for its scientific investigation. Animal Behaviour 130: |4I-I5I. https://doi.org//0.1016/j.anbehav.2017.06.006

Butler RA 1953 Discrimination learning by rhesus monkeys to visual-exploration motivation. Journal of Comparative and Physiological Psychology 46: 95-98. https://doi.org /10.1037/h0061616

Carrol EN and Zuckerman M 1977 Psychopathology and sensation seeking in downers, speeders, and trippers - study of relationship between personality and drug choice. International Journal of the Addictions 12: 59l-60I. https://doi.org/l0.3109 / 10826087709027247

Chapman AL, Gratz KL and Brown MZ 2006 Solving the puzzle of deliberate self-harm: The experiential avoidance model. Behaviour Research and Therapy 44: 37I-394. https://doi.org/10.1016/j.brat.2005.03.005

Cladellas R, Muro A, Vargas-Guzman EA, Bastardas A and Goma-i-Freixanet $\mathbf{M} 2017$ Sensation seeking and high school performance. Personality and Individual Differences II 7: II7121. https://doi.org/10.1016/j.paid.2017.05.049

Clark FE 2013 Marine mammal cognition and captive care: A proposal for cognitive enrichment in zoos and aquariums. Journal of Zoo and Aquarium Research I: I-6

Csikszentmihalyi M 1975 Beyond Boredom and Anxiety. JosseyBass Publishers: San Francisco, USA

Dallaire JA, Meagher RK and Mason GJ 2012 Individual differences in stereotypic behaviour predict individual differences in the nature and degree of enrichment use in caged American mink. Applied Animal Behaviour Science 142: 98-108. https://doi.org/ 10.1016/j.applanim.2012.09.012

de Carvalho CR, Pandolfo P, Pamplona FA and Takahashi RN 2010 Environmental enrichment reduces the impact of novelty and motivational properties of ethanol in spontaneously hypertensive rats. Behavioural Brain Research 208: 23I-236. https://doi.org/10.1016/j.bbr.2009.11.043

Drory A 1982 Individual-differences in boredom proneness and task effectiveness at work. Personnel Psychology 35: |4|-|5I. https://doi.org/10.1 III/j.1744-6570.1982.tb02190.x

Eastwood JD, Frischen A, Fenske MJ and Smilek D 2012 The unengaged mind. Perspectives on Psychological Science 7: 482495. https://doi.org//0.1 I77//74569/6/2456044

Fadel FR, Driscoll P, Pilot M, Wright $\mathbf{H}$, Zulch $\mathbf{H}$ and Mills D 2016 Differences in trait impulsivity indicate diversification of dog breeds into working and show lines. Scientific Reports 6: 22162. https://doi.org//0.1038/srep22162

Fahlman SA, Mercer-Lynn KB, Flora DB and Eastwood JD 2013 Development and validation of the multidimensional state boredom scale. Assessment 20: 68-85. https://doi.org /10.1177/1073191111421303 
Farm Animal Welfare Council 2009 Farm Animal Welfare in Great Britain: Past, Present and Future. Farm Animal Welfare Council: London, UK

Ferland JN, Zeeb FD, Yu K, Kaur S, Taves MD and Winstanley CA 2014 Greater sensitivity to novelty in rats is associated with increased motor impulsivity following repeated exposure to a stimulating environment: implications for the etiology of impulse control deficits. European Journal of Neuroscience 40: 3746-3756. https://doi.org//0.1 I I I/ejn. 12748

FrankI VE 1985 Man's Search for Meaning. Simon and Schuster: New York, NY, USA

Franks B and Higgins ET 2012 Advances in Experimental Social Psychology. Elsevier: San Diego, USA

Frasca D, Tomaszczyk J, McFadyen B and Green R 2013 Traumatic brain injury and post-acute decline: what role does environmental enrichment play? A scoping review. Frontiers in Human Neuroscience 7: 31. https://doi.org//0.3389/fnhum.2013.0003।

Fraser D 1995 Science, values and animal welfare - exploring the inextricable connection. Animal Welfare 4: 103-117

Fraser D 1999 Animal ethics and animal welfare science: bridging the two cultures. Applied Animal Behaviour Science 65: I7I- I89. https://doi.org/I0.1016/S0168-I59I(99)00090-8

Garcia EJ, Haddon TN, Saucier DA and Cain ME 2017 Differential housing and novelty response: Protection and risk from locomotor sensitization. Pharmacology Biochemistry and Behavior 154: 20-30. https://doi.org/10.1016/j.pbb.2017.01.004

Gaygisiz E 2010 Economic and cultural correlates of subjective well-being in countries using data from the Organisation for Economic Co-operation and Development (OECD). Psychological Reports 106: 949-963. https://doi.org//0.2466/pr0.106.3.949-963

German D and Latkin CA 2012 Boredom, depressive symptoms, and HIV risk behaviors among urban injection drug users. AIDS and Behavior 16: 2244-2250. https://doi.org//0.1007/s I046 |-01 2-0247-5

Grimm JW, Osincup D, Wells B, Manaois M, Fyall A, Buse C and Harkness JH 2008 Environmental enrichment attenuates cue-induced reinstatement of sucrose seeking in rats. Behavioural Pharmacology 19: 777-785. https://doi.org// 0.1097 /FBP.0b0/3e3283 I c3b/8

Hall BA, Melfi V, Burns A, McGill DM and Doyle RE 2018 Curious creatures: a multi-taxa investigation of responses to novelty in a zoo environment. Peerf 6: e4454. https://doi.org/ 10.77I7/peerj.4454

Harfeld JL 2013 Telos and the ethics of animal farming. Journal of Agricultural and Environmental Ethics 26: 691-709. https://doi.org// 0.1007/s 10806-012-9422-y

Harris MB 2000 Correlates and characteristics of boredom proneness and boredom. Journal of Applied Social Psychology 30: 576-598. https://doi.org/I0.1 I I I/j.1559-1816.2000.tb02497.x

Havermans RC, Vancleef L, Kalamatianos A and Nederkoorn C 2015 Eating and inflicting pain out of boredom. Appetite 85: 52-57. https://doi.org//0.1016 /j.appet.2014.II.007

Hayward A, Tomlinson A and Neill JC 2016 Low attentive and high impulsive rats: $A$ translational animal model of ADHD and disorders of attention and impulse control. Pharmacology \& Therapeutics 158: 4I-5I. https://doi.org/10.1016/ j.pharmthera.2015.11.010
HM Chief Inspector of Prisons 2015 Report on an unannounced inspection of HMP/YOI Stoke Heath. Her Majesty's Inspectorate of Prisons: London, UK

Honess PE and Marin CM 2006 Behavioural and physiological aspects of stress and aggression in nonhuman primates. Neuroscience and Biobehavioral Reviews 30: 390-412. https://doi.org//0.1016/j.neubiorev.2005.04.003

Inglis IR 1983 Towards a cognitive theory of exploratory behaviour. In: Archer J and Birke LIA (eds) Exploration in Animals and Man PP 72-I 17. Van Nostrand Reinhold: London, UK

Kaba F, Lewis A, Glowa-Kollisch S, Hadler, J, Lee D, Alper H, Selling D, MacDonald R, Solimo A, Parsons A and Venters H 2014 Solitary confinement and risk of self-harm among jail inmates. American Journal of Public Health 104: 442-447. https://doi.org/10.2105/AJPH.2013.301742

Kirkden RD 2000 Assessing motivational strength and studies of boredom and enrichment in pigs. University of Cambridge: Cambridge, UK Kustermans J and Ringmar E 20I I Modernity, boredom, and war: a suggestive essay. Review of International Studies 37: 17751792. https://doi.org//0.1017/S0260210510001038

Leong FTL and Schneller GR 1993 Boredom proneness: Temperamental and cognitive components. Personality and Individual Differences 14: 233-239. https://doi.org/I0.1016/01918869(93)90193-7

Lilley MK, Kuczaj SA and Yeater DB 2017 Individual differences in non-human animals: examining boredom, curiosity, and creativity. In: Vonk J, Weiss A and Kuczaj SA (eds) Personality in Non-human Animals PP 257-276. Springer: Switzerland. https://doi.org/10.1007/978-3-319-59300-5_13

Litva A, Robinson CS and Archer DC 2010 Exploring lay perceptions of the causes of crib凸biting/windsucking behaviour in horses. Equine Veterinary Journal 42: 288-293. https://doi.org/ | 0. 1 | | |/j.2042-3306.2009.00025.x

Lockard RB and Haerer H 1968 Time course of change in light preference resulting from prolonged exposure to adapting stimuli. Journal of Comparative and Physiological Psychology 65: 529-53I. https://doi.org/10.1037/h0025825

Lovallo WR 2013 Early life adversity reduces stress reactivity and enhances impulsive behavior: Implications for health behaviors. International Journal of Psychophysiology 90: 8-16. https://doi.org//0.1016/j.ijpsycho.2012.10.006

Low P, Panksepp J, Reiss D, Edelman D, Van Swinderen B and Koch C 2012 The Cambridge Declaration on Consciousness. Francis Crick Memorial Conference. 7 July 2012, Cambridge, UK

Mackay PC and Wood-Gush DGM 1980 The responsiveness of beef calves to novel stimulation: An interaction between exploration and fear. Applied Animal Ethology 6: 383-384. https://doi.org/I0.1016/0304-3762(80)90141-8

Malkovsky E, Merrifield C, Goldberg $Y$ and Danckert J 2012 Exploring the relationship between boredom and sustained attention. Experimental Brain Research 221 : 59-67. https://doi.org/ 10.1007/s00221-012-3147-z

Maltsberger JT, Sakinofsky I, Jha A and Maltsberger JT 2000 Mansur Zaskar: A man almost bored to death. Suicide and Life-Threatening Behavior 30: 83-90 
Mason G, Burn CC, Dallaire JA, Kroshko J, Kinkaid HM and Jeschke JM 2013 Plastic animals in cages: behavioural flexibility and responses to captivity. Animal Behaviour 85: III3-II26. https://doi.org/10.1016/j.anbehav.2013.02.002

Mason GJ and Burn CC 2018 Frustration and boredom in impoverished environments. In: Appleby MC, Olsson IAS and Galindo F (eds) Animal Welfare, Third Edition PP II4-I38. CABI: Wallingford, UK. https://doi.org/ / 0.1079/978I786390202.0II4

Mather JA and Anderson RC 1999 Exploration, play and habituation in octopuses (Octopus dofleini). Journal of Comparative Psychology 1/3: 333-338. https://doi.org//0.1037/07357036.II3.3.333

Mather JA, Leite TS and Batista AT 2012 Individual prey choices of octopuses: Are they generalist or specialist? Current Zoology 58: 597-603. https://doi.org// 0.1093/czoolo/58.4.597

McFarland D 1989 Problems of Animal Behaviour. Longman: Harlow, UK

Meagher RK, Campbell DLM and Mason GJ 2017 Boredomlike states in mink and their behavioural correlates: A replicate study. Applied Animal Behaviour Science 197: 112-119. https://doi.org/I0.1016/j.applanim.2017.08.00I

Meagher RK, Daros RR, Costa JHC, von Keyserlingk MAG, Hötzel MJ and Weary DM 2015 Effects of degree and timing of social housing on reversal learning and response to novel objects in dairy calves. PLoS One 10: e0I32828. https://doi.org//0.1371/journal.pone.0132828

Meagher RK and Mason GJ 2012 Environmental enrichment reduces signs of boredom in caged mink. PLoS One 7: e49180. https://doi.org/l 0.137//journal.pone.0049180

Meehan CL and Mench JA 2007 The challenge of challenge: can problem solving opportunities enhance animal welfare? Applied Animal Behaviour Science 102: 246-26I. https://doi.org/10.1016/j.applanim.2006.05.03 I

Melton AMA and Schulenberg SE 2007 On the relationship between meaning in life and boredom proneness: examining a logotherapy postulate. Psychological Reports 101: 1016-1022. https://doi.org/10.2466/pr0.101.4.1016-1022

Mench JA 1998 Thirty years after Brambell: Whither animal welfare science? Journal of Applied Animal Welfare Science I: 91-102. https://doi.org/I0.1207/s I 5327604jaws0102_I

MendI M, Burman OHP and Paul ES 2010 An integrative and functional framework for the study of animal emotion and mood. Proceedings of the Royal Society B-Biological Sciences 277: 2895-2904. https://doi.org// 0.1098/rspb.2010.0303

MendI M and Paul ES 2004 Consciousness, emotion and animal welfare: insights from cognitive science. Animal Welfare 13: S25

Menich SR and Baron A 1984 Social housing of rats: Lifespan effects on reaction time, exploration, weight, and longevity. Experimental Aging Research 10: 95-100. https://doi.org// 0.1080/036/0738408258550

Mercer-Lynn KB, Bar RJ and Eastwood JD 2014 Causes of boredom: The person, the situation, or both? Personality and Individual Differences 56: I22-I26. https://doi.org/I0.1016 /j.paid.2013.08.034

Mettke-Hofmann C 2000 Reactions of nomadic and resident parrot species. International Zoo Yearbook 37: 244-256. https://doi.org/I0.I I I I/j. I 748-1090.2000.tb00730.x
Mettke-Hofmann C 2014 Cognitive ecology: ecological factors, lifestyles, and cognition. Wiley Interdisciplinary Reviews-Cognitive Science 5: 345-360. https://doi.org//0.1002/wcs. 1289

Michel G, Carton S and Jouvent R 1997 Sensation seeking and anhedonia in risk taking behaviors. Study in bungee jumpers. EncephaleRevue de Psychiatrie Clinique Biologique et Therapeutique 23: 403-4II

Mikulas WL and Vodanovich SJ 1993 The essence of boredom. Psychological Record 43: 3

Miller R, Bugnyar T, Poelzl K and Schwab C 2015 Differences in exploration behaviour in common ravens and carrion crows during development and across social context. Behavioral Ecology and Sociobiology 69: 1209-1220. https://doi.org//0.1007/s00265-015-1935-8

Morgan KN and Tromborg CT 2007 Sources of stress in captivity. Applied Animal Behaviour Science 102: 262-302. https://doi.org/10.1016/j.applanim.2006.05.032

Nader J, Claudia C, El Rawas R, Favot L, Jaber M, Thiriet $\mathbf{N}$ and Solinas M 2012 Loss of environmental enrichment increases vulnerability to cocaine addiction. Neuropsychopharmacology 37 : |579-1587. https://doi.org//0.1038/npp.20|2.2

Nederkoorn C, Vancleef L, Wilkenhöner A, Claes L and Havermans RC 2016 Self-inflicted pain out of boredom. Psychiatry Research 237: 127-132. https://doi.org /10.1016/j.psychres.2016.01.063

Ng AH, Liu Y, Chen J and Eastwood JD 2015 Culture and state boredom: A comparison between European Canadians and Chinese. Personality and Individual Differences 75: 13-18. https://doi.org/10.1016/j.paid.2014.10.052

Oxford English Dictionary 2017 bore, v.2. Oxford University Press: Oxford, UK

Piazza PV, Deroche V, Deminiere JM, Maccari S, Lemoal M and Simon H 1993 Corticosterone in the range of stressinduced levels possesses reinforcing properties - implications for sensation-seeking behaviors. Proceedings of the National Academy of Sciences of the United States of America 90: 11738-11742. https://doi.org/10.1073/pnas.90.24.11738

Plutchik R 200I The nature of emotions. American Scientist 89: 344-350. https://doi.org//0.15 I I/2001.4.344

Quinn JL, Cole EF, Reed TE and Morand-Ferron J 2016 Environmental and genetic determinants of innovativeness in a natural population of birds. Philosophical Transactions of the Royal Society B: Biological Sciences 37I: 20150I84. https://doi.org /10.1098/rstb.2015.0184

Raine A, Reynolds C, Venables PH and Mednick SA 2002 Stimulation seeking and intelligence: A prospective longitudinal study. Journal of Personality and Social Psychology 82: 663-674. https://doi.org/| 0.1037/0022-35/4.82.4.663

Reader SM 2015 Causes of individual differences in animal exploration and search. Topics in Cognitive Science 7: 45I-468. https://doi.org//0.1 II I/tops. 12148

Ripa CPL, Hansen HS, Mortensen EL, Sanders SA and Reinisch JM 200I A Danish version of the Sensation Seeking Scale and its relation to a broad spectrum of behavioral and psychological characteristics. Personality and Individual Differences 30: |37|-|386. https://doi.org/|0.1016/S0|9|-8869(00)001 |9-7 
Romer D 2010 Adolescent risk taking, impulsivity, and brain development: Implications for prevention. Developmental Psychobiology 52: 263-276. https://doi.org//0.1002/dev.20442

Russell PA 1983 Psychological studies of exploration in animals: a reappraisal. In: Archer J and Birke LIA (eds) Exploration in Animals and Humans PP 22-54. Van Nostrand Reinhold: Wokingham, UK Samuels DJ and Samuels M 1974 Low self-concept as a cause of drug abuse. Journal of Drug Education 4: 42I-438. https://doi.org/ 10.2190/VJHU-MRAR-NLG6-IXBH

Schrijver NCA, Bahr NI, Weiss IC and Würbel H 2002 Dissociable effects of isolation rearing and environmental enrichment on exploration, spatial learning and HPA activity in adult rats. Pharmacology, Biochemistry and Behavior 73: 209-224. https://doi.org/10.1016/S0091-3057(02)00790-6

Seneca LA 1917 Epistle 24. In: Henderson J (ed) Epistles, Volume I: Epistles PP I-65. Harvard University Press: London, UK

Shaw SM, Caldwell LL and Kleiber DA 1996 Boredom, stress and social control in the daily activities of adolescents. Journal of Leisure Research 28: 274-292. https://doi.org/I0.1080/00222216.1996.11949776

Shulman EP, Harden KP, Chein JM and Steinberg L 2015 Sex differences in the developmental trajectories of impulse control and sensation-seeking from early adolescence to early adulthood. Journal of Youth and Adolescence 44: I-17. https://doi.org /10.1007/s 10964-014-0116-9

Snellgrove S, Beck C, Green A and McSweeney JC 2013 Resident-to-resident violence triggers in nursing homes. Clinical Nursing Research 22: 46I-474. https://doi.org/ 10.1 177//0547738/3477/28

Sommers J and Vodanovich SJ 2000 Boredom proneness: Its relationship to psychological- and physical-health symptoms. Journal of Clinical Psychology 56: I49-I55. https://doi.org/I0.1002/(SICI) I0974679(20000 I)56: I<149::AID-JCLPI4>3.0.CO;2-Y

Špinka M 2019 Animal agency, animal awareness and animal welfare. Animal Welfare 28: II-20. https://doi.org/ 10.7I20/09627286.28.1.01।

Špinka $M$ and Wemelsfelder $F 201$ I Environmental challenge and animal agency. In: Appleby MC, Mench JA, Olsson IAS and Hughes BO (eds) Animal Welfare, Second Edition PP 27-44. CAB International: Wallingford, UK. https://doi.org/10.1079/ 9781845936594.0027

Sternberg RJ 2000 Perspectives: Cognition - The Holy Grail of general intelligence. Science 289: 399-40I. https://doi.org/I0.I I 26 /science.289.5478.399

Stolba A and Wood-Gush DGM 1980 Arousal and exploration in growing-pigs in different environments. Applied Animal Ethology 6: 382-383. https://doi.org/10.1016/0304-3762(80)90140-6

Sundberg ND, Latkin CA, Farmer RF and Saoud J 1991 Boredom in young adults. Journal of Cross-Cultural Psychology 22: 209-223. https://doi.org//0.1 I77/002202219/222003

Svendsen PM, Palme R and Malmkvist J 2013 Novelty exploration, baseline cortisol level and fur-chewing in farm mink with different intensities of stereotypic behaviour. Applied Animal Behaviour Science 147: 172-178. https://doi.org/10.1016/j.applanim.2013.05.01 I
Tierney J 2010 The Trotsky. Alliance Films: Canada

Todman M 2003 Boredom and psychotic disorders: Cognitive and motivational issues. Psychiatry 66: 146-167. https://doi.org//0.152I/psyc.66.2.146.20623

Toledo-Rodriguez $\mathbf{M}$ and Sandi C 201 I Stress during adolescence increases novelty seeking and risk-taking behavior in male and female rats. Frontiers in Behavioral Neuroscience 5: 17. https://doi.org/10.3389/fnbeh.201 I.00017

Toohey P 20II Boredom: A Lively History. Yale University Press: London, UK

van der Harst JE, Baars AM and Spruijt BM 2003 Standard housed rats are more sensitive to rewards than enriched housed rats as reflected by their anticipatory behaviour. Behavioural Brain Research 142: 151-156. https://doi.org/10.1016/S01664328(02)00403-5

van der Staay FJ, van Zutphen JA, de Ridder MM and Nordquist RE 2017 Effects of environmental enrichment on decision-making behavior in pigs. Applied Animal Behaviour Science 194: 14-23. https://doi.org/10.1016/j.applanim.2017.05.006 van Horik J and Emery NJ 20II Evolution of cognition. Wiley Interdisciplinary Reviews-Cognitive Science 2: 62I-633. https://doi.org//0.1002/wcs. I44

van Tilburg WAP and Igou ER 2017 Boredom begs to differ: differentiation from other negative emotions. Emotion 17: 309322. https://doi.org// 0.1037/emo0000233

Webster J 2005 Animal Welfare: Limping Towards Eden. Blackwell Publishing: Oxford, UK. https://doi.org/ I 0. I002/978047075 I I 07

Weinstein L, Xie X and Cleanthous CC 1995 Purpose in life, boredom, and volunteerism in a group of retirees. Psychological Reports 76: 482. https://doi.org//0.2466/pr0.1995.76.2.482

Wemelsfelder F 2005 Animal boredom: Understanding the tedium of confined lives. In: McMillan FD (ed) Mental Health and Well-Being in Animals pp 79-92. Blackwell Publishing Ltd: Oxford, UK. https://doi.org// 0.1002/9780470384947.ch6

Wemelsfelder F and Birke LIA 1997 Environmental challenge. In: Appleby MC and Hughes BO (eds) Animal Welfare PP 3547. $C A B$ International: Wallingford, UK.

Wilson TD, Reinhard DA, Westgate EC, Gilbert DT, Ellerbeck N, Hahn C, Brown CL and Shaked A 2014 Just think: The challenges of the disengaged mind. Science 345: 75-77. https://doi.org//0.1 I26/science. 1250830

Wood M, Daniel AM, Daniels E and Papini MR 2006 Effects of housing on consummatory successive negative contrast in rats: wire-bottom cages versus polycarbonate tubs. Lab Animal 35: 3438. https://doi.org//0.1038/laban0306-34

Wood-Gush DGM and Beilharz RG 1983 The enrichment of a bare environment for animals in confined conditions. Applied Animal Ethology 10: 209-217. https://doi.org/10.1016/03043762(83)90142-6

Zakharova E, Miller J, Unterwald E, Wade D and Izenwasser S 2009 Social and physical environment alter cocaine conditioned place preference and dopaminergic markers in adolescent male rats. Neuroscience 163: 890-897. https://doi.org/10.1016/j.neuroscience.2009.06.068 
32 Meagher

Zimbardo PG and Montgomery KC 1957 Effects of 'freeenvironment' rearing upon exploratory behavior. Psychological Reports 3: 589-594

Zuckerman M 197I Dimensions of sensation seeking. Journal of Consulting and Clinical Psychology 36: 45-52. https://doi.org /10.1037/h0030478
Zuckerman M and Link K 1968 Construct validity for the sensation-seeking scale. Journal of Consulting and Clinical Psychology 32: 420-426. https://doi.org//0.1037/h0026047

Porvaldsdottir BM 2014 Effect of environmental enrichment on voluntary salt intake in horses. Hólar University College: Hólar, Iceland 